\title{
Production of an Efficient Magnetic Adsorbent From Babassu Coconut Endocarp and Ni Particles for Easy Dye Removal From Mimetic Contaminated Effluents
}

\section{Wanderson S. Silva}

UFES: Universidade Federal do Espirito Santo

\section{Patrícia F. Santos}

UFES: Universidade Federal do Espirito Santo

Jair C. C. Freitas

UFES: Universidade Federal do Espirito Santo

Miguel A. Schettino

UFES: Universidade Federal do Espirito Santo

Edson C. Passamani

UFES: Universidade Federal do Espirito Santo

Márcia A. M. S. da Veiga

USP: Universidade de Sao Paulo

Priscilla P. Luz ( $\square$ priscilla.luz@ufes.br)

UFES https://orcid.org/0000-0002-9460-546X

\section{Research Article}

Keywords: activated carbon, adsorbent, Ni particles, babassu coconut, methylene blue, wastewater

Posted Date: February 8th, 2021

DOI: https://doi.org/10.21203/rs.3.rs-157234/v1

License: @ (i) This work is licensed under a Creative Commons Attribution 4.0 International License. Read Full License 


\section{Abstract}

$\mathrm{Ni}$ metal particles, with sizes ranging from 70 to $110 \mathrm{~nm}$, dispersed in activated carbon produced from the babassu coconut endocarp (BAC) were successfully synthesized and evaluated by scanning electron microscopy, dispersive energy X-ray spectroscopy, flame atomic absorption spectroscopy and powder Xray diffraction. These hybrid BACNi-X materials (where $X$ is the $\mathrm{Ni} / \mathrm{BAC}$ ratio, equal to 10,20 or 30 ) exhibit crystalline Ni particles with suitable magnetic properties, shown by increased saturation magnetization and a gradual reduction in coercive fields (varying 80 to $150 \mathrm{Oe}$ ) as the Ni content increases. Relatively large values of pore volume (in the range of $0.28-0.37 \mathrm{~cm}^{3} / \mathrm{g}$ ), specific surface area $\left(560-740 \mathrm{~m}^{2} / \mathrm{g}\right)$ are achieved, favoring their applications for magnetic remediation of mimetic contaminated effluents. All hybrid samples were tested positively for the adsorption of methylene blue in contaminated synthetic effluents and the greatest removal was achieved by the hybrid sample BACNi-10, which has the largest specific area and reasonable magnetic properties that allowed the manipulation of the sample by an external field.

\section{Introduction}

Water pollution is one of the world's biggest concerns due to the accumulation of pollutants that are extremely harmful to health. The pollutants of water bodies have both inorganic and organic origin. Among the inorganic pollutants are heavy metals, liberated mainly by different extractive and industrial parcs. The most dangerous contaminants are lead, mercury, zinc, copper, cadmium, iron, chromium, arsenic, among others (Chowdhury et al. 2016; Li et al. 2002; Li et al. 2005; Mousavian et al. 2017; Mubarak et al. 2013; Ogundele et al. 2017; Ruthiraan et al. 2015). The consequences of potentially toxic elements pollution include, in addition to disrupting food chain, the bioaccumulation of these metals in human and animal tissues that also indirectly causes various problems to human health, including not only high probability of developing cancer and central nervous system atrophy, but also mental retardation, gastrointestinal disorders and several other diseases (Li et al. 2002; Mousavian et al. 2017; Acharya et al. 2009).

Among the organic pollutants are dyes, which are widely used in the textile and cellulose industries and are dumped in considerable quantities into waterbodies. Dyes, such as methylene blue, Congo red and others, make water very toxic for human or animal consumption due to the difficulty of degradation and resistance to anaerobic decomposition, leading to problems, such as: dermatitis and respiratory tract issues (Ardejani et al. 2007). However, the greatest risk is the oral ingestion of these compounds because dyes, if catalyzed by specific enzymes in the body, can generate substances with carcinogenic and/or mutagenic properties (Lellis et al. 2019).

Several techniques have been used for the treatment of effluents, like: biofiltration, flow microfiltration, adsorption, electrocoagulation, slow filtration, flocculation, flotation, membrane separation processes, and advanced oxidative processes (Abdel-Ghani and Elchaghaby 2007; Abidi et al. 2015; Alhaji et al. 2016; Krzeminski et al. 2016; Martins et al. 2017; Mohanty et al. 2005; Mullai et al. 2017). Among them, 
the adsorption technique is widely used for the removal of inorganic and organic compounds dissolved in water, which uses low-cost materials, such as: clays, alumina, mesoporous silicas, zeolites and activated carbon as adsorbents (Abidi et al. 2015; Fungaro and Bruno 2009; Tong et al. 2014; Tong et al. 2016).

In water treatments, adsorption on activated carbon is considered one of the most effective techniques, and its advantages include high efficiency in the removal of microcontaminants and ease of operation, in addition to low cost in obtaining the raw material (Al-Degs et al. 2000; Fungaro and Bruno 2009; Tong et al. 2016). Activated carbon can be produced from numerous raw materials with a high carbonaceous content, as: wood, petroleum coke and agricultural residues in general (sugarcane bagasse, straw and corn husks, coffee straw, rice husks and coconut shells) (Coelho et al. 2012). Among these agricultural wastes, we highlight the shells of babassu coconut, which are a byproduct of the exploitation of the babassu palm (Attalea speciosa Mart. ex Spreng) (Cavallari and Toledo 2016). This constitutes an important economic activity in many regions of northeastern Brazil, mainly in the use of almonds, due to the great interest in the extraction of oil to produce biodiesel (Da Rós et al. 2014; Lima et al. 2007). Other potentially relevant uses of this agrowaste include the production of charcoal, activated carbons and cellulosic products (Brito et al. 2019; Emmerich and Luengo 1996; Teixeira 2008).

The adsorbents with magnetic properties have highly been targeted due to their possibility of been removed from the effluent treatment medium with the help of a magnet (Thines et al. 2017). In the work of Liu et al. (2013), $\mathrm{Ni}_{0.5} \mathrm{Zn}_{0.5} \mathrm{Fe}_{2} \mathrm{O}_{4}$ magnetic nanoparticles were synthesized for the adsorption of the methylene blue dye and the subsequent removal of the adsorbent taking advantage of its magnetic properties. In addition, Ruthiraan et al. (2017) obtained surprising results when using a magnetic adsorbent synthesized from the pyrolysis of mangosteen peel and ferric oxide, which showed removal efficiency above $90 \%$ for the adsorption of $\mathrm{Cd}^{2+}$ ions and methylene blue dye. However, there was no clear elucidation as to whether the magnetic particles also contribute to the adsorption capacity or only assist in the removal of the adsorbent. In brief, the above works have shown that the transformation of an activated carbon adsorbent into a magnetic adsorbent can be successfully achieved by introducing elements with ferromagnetic characteristics, as cobalt, nickel, and some iron oxides, into the porous structure of the matrix.

In this sense, this work reports the production of activated carbon from the endocarp of babassu coconut, using the method of physical activation for the development of porosity. In addition, the activated carbon was converted into an adsorbent with magnetic properties by adding metallic nickel to its composition. Then, the material's removal capacity was verified by adsorption tests using a methylene blue dye solution, visible in wastewater at low concentration (1 mg L ${ }^{1}$ ) (Ruthiraan et al. 2017). The obtained results illustrate the benefits of combining the large porosity of the carbonaceous matrix and the ferromagnetic behavior of the Ni particles, leading to the production of low-cost and environmentally friendly magnetic adsorbents with high potential for use in water treatment processes.

\section{Experimental Section}




\section{Materials}

Nickel nitrate hexahydrate $\mathrm{Ni}\left(\mathrm{NO}_{3}\right)_{2} \cdot \mathrm{H}_{2} \mathrm{O}, 98 \%$, Dinâmica Química Contemporânea $\left.{ }^{\circledR}\right)$, sodium hydroxide $\left(\mathrm{NaOH}, 97 \%, \mathrm{QM}^{\mathrm{TM}}\right)$ and methylene blue (MB) (95\%, Sigma-Aldrich $\left.{ }^{\circledR}\right)$ were commercially available and used without prior purification. Babassu coconut was harvested in Açailândia (MA), Brazil.

\section{Preparation of activated carbon}

Activated carbon was prepared from the babassu coconut endocarp, previously separated from the other constituents of the coconut. The endocarp was crushed to obtain a granular material, from which $30.0 \mathrm{~g}$ were submitted to the activation process in a tubular furnace, under argon atmosphere and steam, at a heating rate of $5^{\circ} \mathrm{C} \mathrm{min}-1$ to $800^{\circ} \mathrm{C}$ for $3 \mathrm{~h}$. The injection of water was started when the temperature reached $300{ }^{\circ} \mathrm{C}$, using a peristaltic pump and a physical activation apparatus previously described in Brito et al. (2019). The activated sample was macerated and sieved through a 70-mesh screen (210 $\mu \mathrm{m}$ opening size) to homogenize the macroscopic grain size. The activated carbon produced from the endocarp of babassu coconut was named "BAC" and the activation process was repeated twice, producing $9.0 \mathrm{~g}$ of activated carbon.

\section{Synthesis of Ni particles supported on BAC: hybrid BACNi-X}

Ni particles supported on BAC were successfully synthesized from the BAC precursor and a proportional mass of $\mathrm{Ni}\left(\mathrm{NO}_{3}\right)_{2} \cdot 6 \mathrm{H}_{2} \mathrm{O}$ to obtain samples containing 10,20 and $30 \mathrm{wt}$. \% of $\mathrm{Ni} / \mathrm{BAC}$ ratio, named hybrid BACNi-10, BACNi-20 and BACNi-30, respectively. Firstly, the $\mathrm{Ni}^{2+}$ salt was dissolved in $50.0 \mathrm{~mL}$ of distilled water and then $2.0 \mathrm{~g}$ of BAC were added. This mixture was stirred at $100 \mathrm{rpm}$ at room temperature. After that, an excess of $\mathrm{NaOH}\left(0.1 \mathrm{~mol} \mathrm{~L}^{-1}\right)$ was added until $\mathrm{pH} 12$, at a rate of $0.32 \mathrm{~mL} \mathrm{~min}^{-1}$. The samples were filtered under vacuum and dried for $24 \mathrm{~h}$ at room temperature. Finally, $1.4 \mathrm{~g}$ of each sample were heated at $800{ }^{\circ} \mathrm{C}$, at a heating rate of $5^{\circ} \mathrm{C} \mathrm{min}^{-1}$, under argon atmosphere, to produce Ni particles supported on the activated carbon matrix.

\section{Characterization of the hybrid BACNi-X samples}

A Perkin Elmer AAnalyst 800 flame atomic absorption spectrometer equipped with a deuterium-arc lamp background corrector was used for absorbance measurements at $232.0 \mathrm{~nm}$ for nickel. The operating conditions were those recommended by the manufacturer, unless specified otherwise. Replicate numbers in each analysis were equal to three.

Thermogravimetry (TG) curves were recorded on a Shimadzu ${ }^{T M} T G A-50 H$ thermal analyzer; the samples were heated from 30 to $1000{ }^{\circ} \mathrm{C}$ at a heating rate of $10^{\circ} \mathrm{C} \mathrm{min}-1$ under $\mathrm{O}_{2}$ flow (flow rate of $50 \mathrm{~mL} \mathrm{~min}$ $\left.{ }^{1}\right)$.

Textural analysis was carried out by recording $\mathrm{N}_{2}$ adsorption/desorption isotherms at $77 \mathrm{~K}$ using an Autosorb-1 instrument (Quantachrome Instruments ${ }^{\mathrm{TM}}$ ). The specific surface area values were determined 
by the Brunauer-Emmet-Teller (BET) method, whereas the micro- and mesopore volumes were obtained using the non-local density functional theory (NLDFT) approach (Lowell et al. 2004).

Surface morphology was studied by scanning electron microscopy (SEM) on a Shimadzu SS-550 microscope operating at $15 \mathrm{kV}$, equipped with an accessory module for energy dispersive X-ray spectroscopy (EDX) analyses. The magnetic properties were evaluated on a Quantum Design $\mathrm{s}^{\mathrm{TM}} 6000$ PPMS (Physical Property Measurement System) equipment, using a mass of $0.60 \mathrm{~g}$; the magnetization $(\mathrm{M})$ as a function of magnetic field $(\mathrm{H})$ curves were recorded at room temperature $(300 \mathrm{~K})$ with a maximum sweep $\mathrm{H}$-field of $6.0 \mathrm{kOe}$.

The powder X-Ray diffraction (PXRD) patterns were recorded on a Shimadzu ${ }^{\mathrm{TM}}$ XRD-6000 diffractometer, operating at $40 \mathrm{kV}$ and $30 \mathrm{~mA}$, using Cu Ka radiation $(\lambda=1.5406 \AA)$, in the $2 \theta$ range from 10 to $80^{\circ}$ at a rate of $0.002^{\circ} \mathrm{min}^{-1}$. The obtained diffraction patterns were analyzed and compared with the crystallographic structures provided by the Joint Committee on Powder Diffraction Standards (JCPDS), International Centre for Diffraction Data (ICDD), available in PCPDFWIN software version 2.3 (PCPDFWIN 1996). In addition, the obtained X-ray diffractograms were adjusted using the software MAUD (Materials Analysis Using Diffraction) (freeware) (Lutterotti et al. 2010). The fittings of the PXRD patterns were performed to determine the average crystallite sizes and the volume fractions of the crystalline phases present in the analyzed samples.

\section{Adsorption behavior of the hybrid BACNi-X samples}

For the adsorption tests of MB by hybrid BACNi- $X$ materials $(X=10,20$ and 30$)$, a three leveled $(-1,0,+1)$ full factorial design was performed to evaluate the influence and the interaction of independent variables (Ni content in activated carbon and adsorption time) on the response variable (concentration of the MB solution after adsorption). The values of the independent variables for each level are the following: nominal Ni/BAC ratio (wt. \%) 10(-1), 20(0) and 30(+ 1), and adsorption times (min) 15(-1), 45(0) and 60(+ 1). The combination between them and the correspondent experiment denominations are shown in Table 1.

The adsorptions were performed at room temperature by adding, separately, $5 \mathrm{mg}$ of each hybrid BACNi-X sample in $10 \mathrm{~mL}$ of a mimetic contaminated effluents composed by $20 \mathrm{ppm}$ MB aqueous solution. After the adsorption times (Table 1), the hybrid BACNi-X samples were removed from the solution and the remaining MB concentration was evaluated on a UV-VIS Lambda 45 PerkinElmer spectrophotometer operating at $664 \mathrm{~nm}$.

The results were analyzed from the Effect Table and the Response Surface Graph generated by the Statistica Software (Stat Soft Inc 2014). In addition to the factorial design results, the adsorption process was carried out in pure activated carbon (BAC-0) with the same adsorption time variation, in order to verify the role played by the presence of the Ni particles on the adsorption process. 
Table 1

Experiments performed and the respective combination of the independent variable levels.

\begin{tabular}{|c|c|c|}
\hline & Factor 1 & Factor 2 \\
\hline Experimental conditions & $\mathrm{Ni} / \mathrm{BAC}$ ratio in wt. \% (level/x) & Adsorption time in $\min ($ level/y) \\
\hline 1 (BAC-10\%-15 min) & $10(-1)$ & $15(-1)$ \\
\hline 2 (BAC-20\%-15 min) & $20(0)$ & $15(-1)$ \\
\hline 3 (BAC-30\%-15 min) & $30(+1)$ & $15(-1)$ \\
\hline 4 (BAC-10\%-45 min) & $10(-1)$ & $45(0)$ \\
\hline 5 (BAC-20\%-45 min) & $20(0)$ & $45(0)$ \\
\hline 6 (BAC-30\%-45 min) & $30(+1)$ & $45(0)$ \\
\hline 7 (BAC-10\%-60 min) & $10(-1)$ & $60(+1)$ \\
\hline 8 (BAC-20\%-60 min) & $20(0)$ & $60(+1)$ \\
\hline 9 (BAC-30\%-60 min) & $30(+1)$ & $60(+1)$ \\
\hline
\end{tabular}

\section{Results And Discussion}

\section{Determination of the Ni content}

The Ni content in hybrid BACNi-10, BACNi-20 and BACNi-30 samples were determined by FAAS and the found values are 13, 23 and $27 \mathrm{wt}$. \%, respectively (Table 2). These values are reasonably close to the initial Ni contents $(10,20$ and $30 \mathrm{wt}$. \%, respectively). The differences between the actual and the nominal $\mathrm{Ni} / \mathrm{BAC}$ ratios can be due to the loss of carbonaceous matrix during the heat treatments at $800{ }^{\circ} \mathrm{C}$ applied to convert the nickel hydroxide into metallic nickel particles.

\section{Thermal analysis}

The thermal behavior of the hybrid BACNi-X samples under oxidizing atmosphere are shown in Fig. 1. The first decomposition step is observed up to $115^{\circ} \mathrm{C}$ and corresponds to the release of adsorbed water, with weight losses of $5 \%$ for the pure BAC sample and $3 \%$ for all hybrid BACNi- $X$ samples. The second decomposition step occurs between 450 and $500{ }^{\circ} \mathrm{C}$, with weight losses of $88,75,63$ and $59 \%$ to BAC, BACNi-10, BACNi-20 e BACNi-30, respectively. This step corresponds to the oxidation process of the carbonaceous matrix and the reduction of the weight losses (i.e., the fixed carbon contents) with the increase in the Ni contents is obviously associated with the growth of the ash contents. In addition, it is observed a synergism between the Ni/BAC ratios and the thermal stability of each sample, with the oxidation temperature increasing along with the $\mathrm{Ni} / \mathrm{BAC}$ ratio.

\section{Textural analysis}


The adsorption and desorption isotherms of $\mathrm{N}_{2}$ at $77 \mathrm{~K}$ for the pure BAC and hybrid BACNi-10, BACNi-20 and BACNi-30 samples are shown in Fig. 2. These curves are similar to type I isotherms, due to the abrupt increase in the adsorbed amount of $\mathrm{N}_{2}$ at low relative pressures, which is a feature typical of microporous materials (Lowell et al. 2004; Sing 1985). Also, the specific surface area values and the volumes of micro/mesopores are also shown in Table 2. As expected, the pure BAC sample presents the largest specific surface area, corresponding to $824 \mathrm{~m}^{2} \mathrm{~g}^{-1}$, while for the hybrid BACNi-X samples, the inclusion of the Ni particles causes a reduction of the specific surface area values, being equal to 741, 608 and $561 \mathrm{~m}^{2} \mathrm{~g}^{-1}$ for the hybrid BACNi-10, BACNi-20 and BACNi-30 samples, respectively. Therefore, the lower the Ni/BAC ratio, the higher the specific surface area. These results are satisfactory, since other activated carbons obtained by physical activation typically exhibit specific surface area values in the range of 200-1300 $\mathrm{m}^{2} \mathrm{~g}^{-1}$ (Nabais et al. 2008; Reddy et al. 2013; Rodriguez-Reinoso et al. 1995; Sun and Jiang 2010). The pore volumes of the hybrid BACNi-X samples follow the same trend of the specific surface area as a function of the increase of Ni/BAC ratio. All hybrid samples exhibit micropore volumes accounting for $85-89 \%$ of the total pore volume. It is interesting to note that the mesopore contribution to the total pore volume increases slightly with the increase of the Ni content.

The main reason for the decrease in the specific surface area values and pore volumes as a function of the $\mathrm{Ni} / \mathrm{BAC}$ ratio is the effective reduction in the mass fraction of the porous carbon matrix (as revealed by the TG results) in the hybrid BACNi-X samples. Moreover, it is possible that some obstruction of the porous structure of the activated carbon also contributes to the porosity reduction in the composite samples. It is also worth pointing out that the increase in the relative fraction of mesopores in the total pore volume of the hybrid BACNi-X samples can be associated with the surface contribution of the Nicontaining particles, similarly to what has been observed in other nanostructured systems (Gonçalves et al. 2015).

Table 2

$\mathrm{Ni}$ content and textural properties of the pure BAC and hybrid BACNi-10, BACNi-20, BACNi-30 samples

\begin{tabular}{|lllll|}
\hline Samples & Ni content (wt. \%) & $\mathbf{S}_{(B E T)}\left(\mathrm{m}^{2} \mathbf{g}^{-1}\right)$ & $V_{\text {micropore }}\left(\mathrm{cm}^{3} \mathbf{g}^{-1}\right)$ & $V_{\text {mesopore }}\left(\mathrm{cm}^{\mathbf{3}} \mathbf{g}^{-1}\right)$ \\
\hline BAC & - & 824 & 0.326 & 0.039 \\
\hline BACNi-10 & 13 & 741 & 0.328 & 0.046 \\
\hline BACNi-20 & 23 & 608 & 0.258 & 0.046 \\
\hline BACNi-30 & 27 & 561 & 0.241 & 0.043 \\
\hline
\end{tabular}

\section{Particles morphology}

SEM and TEM images of the hybrid BACNi-10, BACNi-20 and BACNi-30 samples are shown in Fig. 3. It is possible to see submicron spherical particles homogeneously dispersed on the carbonaceous matrix (Zieliński et al. 2007). A selected area of the hybrid BACNi-10 sample, demarcated by a red square in 
Fig. 3(a), was submitted to EDX analysis. It shows the distribution of the elements carbon (intense peak) and low signals due to oxygen and $\mathrm{Ni}$ atoms. These results clearly indicate the presence of submicron $\mathrm{Ni}$ containing spherical particles on the surface of the hybrid BACNi-X samples.

\section{Structural characterization}

The PXRD patterns of all synthesized samples are shown in Fig. 4. The diffractogram of the pure BAC sample exhibits broad peaks at ca. $23^{\circ}$ and $43^{\circ}$, assigned to the (002) and (200) reflections of the turbostratic structure of the carbon matrix (Carreño et al. 2002; Li et al. 2007; Silva and Rezende 2018; Zanoteli et al. 2014). A small peak ascribed to silicon dioxide $\left(\mathrm{SiO}_{2}\right)$ is also detected at $22.4^{\circ}$, in accordance with Freitas et al. (2000), that assigned this peak around $22^{\circ}$ and it is a consequence of the natural occurrence of Si-containing compounds in the endocarp of babassu coconut. Besides, the diffractograms of the hybrid BACNi-10, BACNi-20 and BACNi-30 samples show two intense diffraction peaks at $44.5^{\circ}$ and $51.9^{\circ}$ and a lower intense peak at $76.5^{\circ}$, which correspond to (111), (200) and (222) reflections, respectively, of the face centered cubic (fcc) structure of the metallic Ni (Zieliński et al. 2007). A remaining phase of nickel oxide $(\mathrm{NiO})$ in the material is present in all hybrid $\mathrm{BACNi}-\mathrm{X}$ samples, identified by low intensity diffraction peaks at $37.3^{\circ}, 43.3^{\circ}$ and $62.9^{\circ}$, associated with the reflections (111), (200) and (220) of the fcc structure of NiO, respectively (Zieliński et al. 2007). Finally, the presence of $\mathrm{Ni}$ and $\mathrm{O}$ atoms in the X-ray diffractograms agrees with the EDX map shown in Fig. 3(a).

The PXRD patterns of the hybrid BACNi-X samples were adjusted using the MAUD software (Lutterotti et al. 2010), as illustrated in Fig. 5 for a representative sample. These structure refinements allowed the calculation of the volume fraction of each crystalline phase ( $\mathrm{Ni}$ and $\mathrm{NiO}$ ) and the determination of the corresponding average crystallite sizes, which are listed in Table 3. These results show that both the $\mathrm{Ni}$ and the $\mathrm{NiO}$ average crystallite sizes increase as the $\mathrm{Ni} / \mathrm{BAC}$ ratio increase. At the same time, the volume fraction of the metallic Ni phase also grows, reaching a value close to $90 \%$ for the hybrid BACNi-30 sample. It is important to note that these crystallite sizes are somewhat smaller than the Ni particle sizes observed in the SEM and TEM images shown in Fig. 3 (albeit they are all the same order of magnitude), thus suggesting a polycrystalline nature for those particles (Gonçalves et al. 2015). 
Table 3

Volume fractions and average crystallite sizes of the crystalline phases identified in the PXRD patterns of the hybrid BACNi-X samples

\begin{tabular}{|llll|}
\hline Samples & Phase & Crystalline phase content $(\%)$ & $\mathbf{t}(\mathbf{n m})( \pm 1 \mathrm{~nm})$ \\
\hline BACNi-10 & $\mathrm{Ni}$ & 69.7 & 66 \\
& $\mathrm{NiO}$ & 30.3 & 12 \\
\hline \multirow{2}{*}{ BACNi-20 } & $\mathrm{Ni}$ & 78.0 & 69 \\
& $\mathrm{NiO}$ & 22.0 & 14 \\
\hline \multirow{2}{*}{ BACNi-30 } & $\mathrm{Ni}$ & 89.6 & 116 \\
& $\mathrm{NiO}$ & 10.4 & 18 \\
\hline
\end{tabular}

\section{Magnetic properties}

The magnetic properties of the hybrid BACNi-10, BACNi-20 and BACNi-30 samples were investigated by recording the magnetization ( $\mathrm{M} v s . \mathrm{H})$ curves shown in Fig. 6 . These curves clearly reveal the ferromagnetic character of the analyzed materials (magnetic saturation regime and non-zero coercive field). In particular, the hysteresis $\mathrm{M}(\mathrm{H})$ cycles present coercive field $\left(\mathrm{H}_{\mathrm{c}}\right)$ ca. $100 \mathrm{Oe}$, as observed in the inset of Fig. 7, and informed in Table 4. Thus, it reflects the soft-like ferromagnetic character of the Ni nanoparticles. The values of the saturation magnetization $\left(\mathrm{M}_{\mathrm{s}}\right.$ in $\left.\mathrm{emu} / \mathrm{g}\right)$ are also given in the same table. As can be seen, Fig. 6 clearly shows a correlation of $\mathrm{M}_{\mathrm{s}}$ with the content of metallic $\mathrm{Ni}$ in the samples (estimated from the PXRD results and considering the bulk densities of $\mathrm{Ni}$ and $\mathrm{NiO}$ ). This trend is understandable, since the $\mathrm{NiO}$ phase (exhibiting bulk antiferromagnetic behavior at room temperature) is not expected to contribute significantly to the saturation magnetization of the hybrid BACNi- $X$ samples, which is, therefore, chiefly determined by the content of the ferromagnetic phase (metallic $\mathrm{Ni}$ ) in these materials (Coey 2009).

As for the coercive field, the decrease of $\mathrm{H}_{\mathrm{C}}$ as a function of the Ni content can be understood considering that relatively large ferromagnetic particles, as those observed in the SEM images (Fig. 3), preferably form multiple magnetic domains, for which the coercive field is expected to be low (Crangle and Goodman 1971; Leslie-Pelecky and Rieke 1996). On the other hand, when the ferromagnetic particles exhibit sizes below a give critical diameter (around $55 \mathrm{~nm}$ for $\mathrm{Ni}$ ), the formation of magnetic single domains is preferred and the coercive field increases, because changes in the magnetization can no longer occur by modifications in the multi domain structure (e.g., domain walls displacement) and must be accomplished by the rotation of the magnetic moments of the whole single domain particles (Coey 2009). In the case of the hybrid BACNi-X samples, the PXRD results indicate that the average crystallite size of the metallic $\mathrm{Ni}$ phase grows with the increase in the Ni content (Table 3), which, in the mentioned scenario, explains the trend of reduction of the $\mathrm{H}_{\mathrm{c}}$ values, also considering that these materials are composed of Ni-containing ferromagnetic particles with a broad size distribution (Khan et al. 2020). 
Table 4

Total Ni content determined by FAAS and by PXRD, saturation magnetization $\left(\mathrm{M}_{\mathrm{s}}\right)$ and coercive field $\left(\mathrm{H}_{\mathrm{c}}\right)$ of the hybrid BACNi-X samples

\begin{tabular}{|llllll|}
\hline Samples & Ni content (wt. \%)* & Metallic Ni content (wt. \%)** & $\mathbf{M}_{\mathbf{s}}(\mathbf{e m u} / \mathbf{g})$ & $\mathbf{H}_{\mathbf{c}}(\mathbf{O e})$ \\
\hline BACNi-10 & 13 & 9.8 & 3.3 & 150.0 \\
\hline BACNi-20 & 23 & 19.0 & 6.2 & 113.1 \\
\hline BACNi-30 & 27 & 24.8 & 12.3 & 84.4 \\
\hline * Ni contents determined by FAAS. & & \\
\hline ** Ni content calculated by PXRD (after considering the densities of the Ni and NiO phases).
\end{tabular}

\section{Statistical analysis of the adsorptive capacity of the hybrid BACNi-X samples}

The adsorption process results, obtained in the factorial design experiments, are summarized in Table 5. The value of the response variable corresponds to the concentration of the MB solution at the end of the adsorption process conducted for each sample, indicating the adsorption capacity of the hybrid BACNi-X samples.

The adsorption process (Fig. 7) shows a better result for the test performed with a longer adsorption time (60 min), firstly evidencing the importance of this parameter for the efficient removal of the organic dye from a synthetic solution, and secondly improving the adsorption process in the pores of the adsorbent materials. In addition, the sample with the lowest Ni/BAC ratio (BACNi-10) and the highest specific surface area showed the best adsorption result, evidenced by the lower remaining concentration of MB in solution (5.47 ppm). This relatively low amount of $\mathrm{Ni}$ in this material is sufficient to allow the removal of the magnetic adsorbent from the MB synthetic solution by magnetic attraction (Calimli et al. 2020; Kim et al. 2018; Tao et al. 2019).

Table 5

Results of the factorial design experiments for the adsorption process of MB by the hybrid BACNi-X samples

\begin{tabular}{|lllll|}
\hline \multicolumn{3}{|c|}{ Variable Response: Methylene Blue Concentration (ppm) } \\
\hline Samples & Ni/BAC ratio (wt. \%) & \multicolumn{3}{c|}{ Adsorption time (min) } \\
\cline { 3 - 6 } & & 15 & 45 & 60 \\
\hline BACNi-10 & 13 & 9.23 & 8.42 & 5.47 \\
\hline BACNi-20 & 23 & 9.17 & 9.17 & 7.80 \\
\hline BACNi-30 & 27 & 9.17 & 9.17 & 8.77 \\
\hline
\end{tabular}


The Effect Table, Table 6, presents the effect of an independent variable and the interaction between independent variables (the factors) in a dependent variable (the response variable), within a $95 \%$ confidence limit. The $p$-value describes the probability of result significance, in which values smaller than $0.05 \%$ indicate that a certain factor exerted influence on the response variable. From the interpretation of the statistical model, only the interaction between factors influences considerably the response variable value ( $p$-value $=0.000009$ ); therefore, the combination between Ni concentration and adsorption time presents greater significance in the result (Amorim et al. 2018; Santos and Luz 2020).

The Factor 2 (adsorption time) influences the variable response (concentration of the MB solution after adsorption), so that longer adsorption times leads to lower dye concentrations, thus indicating higher adsorption of MB by the hybrid BACNi-X samples. Oppositely, the Factor 1 influences negatively the response variable, since the increase in $\mathrm{Ni} / \mathrm{BAC}$ ratio (with the consequent reduction in the specific surface area values and pore volumes) results in a more concentrated solution, which means lower adsorption by the hybrid BACNi-X samples.

Table 6

Effect Table for the adsorption process of MB by the hybrid BACNi-X samples

\begin{tabular}{|llllll|}
\hline Factor & Effect & Std.Err. & Coefficient & Std.Err. & p-value \\
\hline Mean/interactions & 8.59 & 0.30 & 8.59 & 0.30 & $9.0 \times 10^{-6}$ \\
Ni/BAC ratio & 1.33 & 0.74 & 0.67 & 0.37 & $1.45 \times 10^{-1}$ \\
(wt. \%) (L) & & & & & \\
\hline $\begin{array}{l}\text { Ni/BAC ratio } \\
\text { (wt. \%) (Q) }\end{array}$ & 0.34 & 0.64 & 0.17 & 0.32 & $6.20 \times 10^{-1}$ \\
\hline Adsorption time (min) (L) & -1.84 & 0.74 & -0.92 & 0.37 & $6.62 \times 10^{-2}$ \\
\hline Adsorption time (min) (Q) & 0.96 & 0.65 & 0.48 & 0.32 & $2.13 \times 10^{-1}$ \\
\hline
\end{tabular}

The coefficients of Effect Table were used to construct a mathematical model that describes the interactions between the two factors studied at three levels, and the obtained equation is:

$z(x, y)=8.59+0.67 x+0.17 x^{2}-0.92 y+0.48 y^{2}(1)$

where $y$ is the response variable, $x_{1}$ corresponds to Ni/BAC ratio (Factor 1 ) and $x_{2}$ is the adsorption time (Factor 2).

The Surface Graph, Fig. 8, shows a three-dimensional relation of the factors and allows a visual analysis of the results, represented by a uniform surface. The independent variables (Factors 1 and 2 ) are found on the $x$ and $y$ axes, and the response variable on the $z$ axis. 
These results then show that it is possible to prepare efficient magnetic adsorbents containing submicron Ni particles dispersed in biomass-derived activated carbons, using a simple impregnation route followed by heat treatments. The use of a relatively low Ni loading ( $13 \mathrm{wt} . \%)$ allows the production of a magnetic adsorbent with sizeable porosity (specific surface area $\sim 740 \mathrm{~m}^{2} \mathrm{~g}^{-1}$ ) that can remove a large amount of methylene blue in aqueous solution. Furthermore, this material exhibits strong ferromagnetic properties at room temperature, which allow the easy separation of the magnetic adsorbent from the aqueous solution after the end of the adsorption process. Finally, it is worth stressing that, although this work is concerned only with the adsorptive properties of the produced hybrids, these materials composed of submicron Ni-containing particles supported on a porous matrix are of potentially high interest for applications in fields such as heterogeneous catalysis and hydrogen storage, among others (Zieliński et al. 2007; Careño et al. 2002; Zanoteli et al. 2014; Li et al. 2010; Donald et al. 2010).

\section{Conclusion}

The successful synthesis of submicron Ni particles dispersed in biomass-derived activated carbons gave rise to stable and magnetic adsorbents useful for the adsorption of methylene blue from mimetic contaminated effluents and that can be easily separated from the aqueous medium using a magnet. The predominance of metallic Ni particles, evidence by the analysis of X-ray diffraction results, is responsible for the magnetic behavior of the adsorbents, even at the lowest Ni loading ( 13 wt. \%). The presence of the Ni particles reduces the specific values of pore volume and surface area of the prepared samples due to the reduction of the fraction of the material effectively associated with the porous carbon matrix. By a $\left(2^{3}\right)$ factorial design for the adsorption of methylene blue by the hybrid BACNi-X samples, a satisfactory adsorption and magnetic separation are obtained for the hybrid BACNi-10 sample at 60 min of contact with the dye synthetic solution, evidencing the benefits of combining the large porosity and the ferromagnetic behavior of the produced adsorbents. These results show then that it is possible to prepare efficient Ni-containing magnetic adsorbents using activated carbons derived from a lignocellulosic waste material and following a simple impregnation route followed by heat treatments. A small amount of $\mathrm{Ni}$ is sufficient to carry out the magnetic separation process while preserving the porous structure of the material and thus ensuring a good adsorption efficiency.

\section{Declarations}

\section{Ethics approval and consent to participate}

Not applicable.

\section{Consent for publication}

Not applicable.

\section{Availability of data and materials}


All data generated or analysed during this study are included in this published article.

\section{Competing interests}

The authors declare that they have no competing interests.

\section{Funding}

The authors thank the CAPES (Coordenação de Aperfeiçoamento de Pessoal de Nível Superior) - Brasil Finance Code 001. FAPES (Fundação de Amparo à Pesquisa e Inovação do Espírito Santo) for the financial support by means of the grant $n^{\circ} 85201154$ (Programa Primeiros Projetos).

\section{Authors' contributions}

Conceptualization: Wanderson Silva, Priscilla P. Luz;

Methodology: Wanderson Silva, Patrícia F. Santos, Priscilla P. Luz;

Formal analysis and investigation: Wanderson Silva, Patrícia F. Santos, Miguel A. Schettino Jr, Jair C. C. Freitas, Edson C. Passamani, Márcia A. M. S. da Veiga;

Writing - original draft preparation: Wanderson Silva;

Writing - review and editing: Patrícia F. Santos, Jair C. C. Freitas, Edson C. Passamani, Márcia A. M. S. da Veiga, Priscilla P. Luz;

Funding acquisition: Priscilla P. Luz;

Resources: Priscilla P. Luz, Jair C. C. Freitas, Miguel A. Schettino Jr, Edson C. Passamani, Márcia A. M. S. da Veiga;

Supervision: Priscilla P. Luz.

\section{Acknowledgments}

The authors thank the Brazilian agencies CAPES (Coordenação de Aperfeiçoamento de Pessoal de Nível Superior) and FAPES (Fundação de Amparo à Pesquisa e Inovação do Espírito Santo) for the scholarships and for the financial supports, Finance Code 001 and grant $n^{\circ} 85201154$ (Programa Primeiros Projetos), respectively.

\section{References}

Abdel-Ghani NT, Elchaghaby GA (2007) Influence of operating conditions on the removal of Cu, Zn, Cd and $\mathrm{Pb}$ ions from wastewater by adsorption. Int $\mathrm{J}$ Environ Sci Technol 4:451-456.

https://doi.org/10.1007/BF03325980 
Abidi N, Errais E, Duplay J, Berez A, Jrad A, Schäfer G, Ghazi M, Semhi K, Trabelsi-Ayadia M (2015) Treatment of dye-containing effluent by natural clay. J Clean Prod 86:432-440. https://doi.org/10.1016/j.jclepro.2014.08.043

Acharya S, Dilnawaz F, Sahoo SK (2009) Targeted epidermal growth factor receptor nanoparticle bioconjugates for breast cancer therapy. Biomaterials 30:5737-5750.

https://doi.org/10.1016/j.biomaterials.2009.07.008

Al-Degs Y, Khraisheh MAM, Allen SJ, Ahmad MN (2000) Effect of carbon surface chemistry on the removal of reactive dyes from textile effluent. Water Res 34:927-935. https://doi.org/10.1016/S00431354(99)00200-6

Alhaji MH, Sanaullah K, Lim S-F, Khan A, Hipolito CN, Abdullah MO, Bhawani SA, Jamil T (2016) Photocatalytic treatment technology for palm oil mill effluent (POME) - A review. Process Saf Environ Prot 102:673-686. https://doi.org/10.1016/j.psep.2016.05.020

Amorim HIS, Santos PF, Filgueiras PR, Luz PP (2018) Factorial Design and Evaluation of the Influence of $\mathrm{Cu}^{2+}$ Salts Counterions on the Synthesis of MOF 199. Orbital: Electron J Chem 10:543-551. http://dx.doi.org/10.17807/orbital.v10i7.1213

Ardejani FD, Badii K, Limaee NY, Mahmoodi NM, Arami M, Shafaei SZ, Mirhabibi AR (2007) Numerical modelling and laboratory studies on the removal of Direct Red 23 and Direct Red 80 dyes from textile effluents using orange peel, a low-cost adsorbent. Dye Pigment 73:178-185.

https://doi.org/10.1016/j.dyepig.2005.11.011

Brito GM, Cipriano DF, Schettino MA, Cunha AG, Coelho ERC, Freitas JCC (2019) One-step methodology for preparing physically activated biocarbons from agricultural biomass waste. J Environ Chem Eng 7:103113. https://doi.org/10.1016/j.jece.2019.103113

Calimli MH, Nas MS, Burhan H, Mustafov SD, Demirbas O, Sen F (2020) Preparation, characterization, and adsorption kinetics of methylene blue dye in reduced-graphene oxide supported nanoadsorbents. J Mol Liq 309: 113-171. https://doi.org/10.1016/j.molliq.2020.113171

Carreño NLV, Leite ER, Santos LPS, Lisboa-Filho PN, Longo E (2002) Síntese, caracterização e estudo das propriedades catalíticas e magnéticas de nanopartículas de $\mathrm{Ni}$ dispersas em matriz mesoporosa de $\mathrm{SiO}_{2}$. Quim Nova 25:935-942. https://doi.org/10.1590/S0100-40422002000600010.

Cavallari MM, Toledo MM (2016) What is the name of the babassu? A note on the confusing use of scientific names for this important palm tree. Rodriguésia 67:533-538. https://doi.org/10.1590/21757860201667218

Chowdhury S, Mazumder MAJ, Al-Attas O, Husain T (2016) Heavy metals in drinking water: Occurrences, implications, and future needs in developing countries. Sci Total Environ 569-570:476-488. 
https://doi.org/10.1016/j.scitotenv.2016.06.166

Coelho ERC, Vazzoler H, Leal WP (2012) Emprego do carvão ativado para remoção de atrazina em água de abastecimento público. Eng Sanit Ambient 17:421-428. https://doi.org/10.1590/S141341522012000400009

Coey JMD (2009) Magnetism and Magnetic Materials, Cambridge University Press, Cambridge.

Crangle J, Goodman GM (1971) The magnetization of pure iron and nickel. Proc. R. Soc. 321:477-491. https://doi.org/10.1098/rspa.1971.0044

Da Rós PCM, Silva WC, Grabauskas D, Perez VH, Castro HF (2014) Biodiesel from babassu oil: Characterization of the product obtained by enzymatic route accelerated by microwave irradiation. Ind Crops Prod 52:313-320. https://doi.org/10.1016/j.indcrop.2013.11.013

Donald J, Xu CC, Hashimoto H, Byambajav E, Ohtsuka Y (2010) Novel carbon-based Ni/Fe catalysts derived from peat for hot gas ammonia decomposition in an inert helium atmosphere. Appl Catal A-Gen 375:1124-133. https://doi.org/10.1016/j.apcata.2009.12.030

Emmerich FG, Luengo CA (1996) Babassu charcoal: A sulfurless renewable thermo-reducing feedstock for steelmaking. Biomass Bioenerg 10:41-44. https://doi.org/10.1016/0961-9534(95)00060-7

Freitas JCC, Emmerich FG, Bonagamba TJ (2000) High-Resolution Solid-State NMR Study of the Occurrence and Thermal Transformations of Silicon-Containing Species in Biomass Materials. Chem Mater 12:711-718. https://doi.org/10.1021/cm990472g

Fungaro DA, Bruno M. (2009) Remoção de azul de metileno de solução aquosa usando zeólitas sintetizadas com amostras de cinzas de carvão diferentes. Quim Nova 32:955-959. http://dx.doi.org/10.1590/S0100-40422009000400024

Gonçalves GR, Schettino MA, Morigaki MK, Nunes E, Cunha AG, Emmerich FG, Passamani EC, BaggioSaitovitch E, Freitas JCC (2015) Synthesis of nanostructured iron oxides dispersed in carbon materials and in situ XRD study of the changes caused by thermal treatment. J Nanoparticle Res 17:303. https://doi.org/10.1007/s11051-015-3092-4

Khan FSA, Mubarak NM, Tan YH, Karri RR, Khalid M, Walvekar R, Abdullah EC, Mazari SA, Nizamuddin S (2020) Magnetic nanoparticles incorporation into different substrate for dyes and heavy metals removal -A Review. Environ Sci Pollut Res. https://doi.org/10.1007/s11356-020-10482-z

Kim T-S, Song HJ, Dar MA, Lee H-J, Kim D-W (2018) Fast adsorption kinetics of highly dispersed ultrafine nickel/carbon nanoparticles for organic dye removal. Appl Surf Sci, 439:364-370. https://doi.org/10.1016/j.apsusc.2018.01.061 
Krzeminski, P., Schwermer, C., Wennberg, A., Langford, K. \&Vogelsang, C. Occurrence of UV filters, fragrances and organophosphate flame retardants in municipal WWTP effluents and their removal during membrane post-treatment. J. Hazard. Mater. (2016). https://doi.org/10.1016/j.jhazmat.2016.08.001

Lellis B, Fávaro-Polonio CZ, Pamphile JA, Polonio JC (2019) Effects of textile dyes on health and the environment and bioremediation potential of living organisms. Biotechnol Res Innov 3:275-290. https://doi.org/10.1016/j.biori.2019.09.001

Leslie-Pelecky DL, Rieke RD (1996) Magnetic Properties of Nanostructured Materials. Chem Mater 8:1770-1783. https://doi.org/10.1021/cm960077f

Li H, Yu D, Hu Y, Sun P, Xia J, Huang H (2010) Effect of preparation method on the structure and catalytic property of activated carbon supported nickel oxide catalysts. Carbon 48:4547-4555.

https://doi.org/10.1016/j.carbon.2010.08.038

Li Y-H, Di Z, Ding J, Wu D, Luan Z, Zhu Y (2005) Adsorption thermodynamic, kinetic and desorption studies of $\mathrm{Pb}^{2+}$ on carbon nanotubes. Water Res 39:605-609.

https://doi.org/10.1016/j.watres.2004.11.004

Li Y-H, Wang S, Wei J, Zhang X (2002) Lead adsorption on carbon nanotubes. Chem Phys Lett 357:26266. https://doi.org/10.1016/S0009-2614(02)00502-X

Li ZQ, Lu CJ, Xia ZP, Zhou Y, Luo Z (2007) X-ray diffraction patterns of graphite and turbostratic carbon. Carbon45:1686-1695. https://doi.org/10.1016/j.carbon.2007.03.038

Lima JRO, Silva RB, Silva CCM, Santos LSS, Santos JR, Moura EM, Moura CVR (2007) Biodiesel de babaçu (Orbignya sp.) obtido por via etanólica. Quim Nova 30:600-603. https://doi.org/10.1590/S010040422007000300019

Liu R, Shen X, Yang X, Wang Q, Yang F (2013) Adsorption characteristics of methyl blue onto magnetic

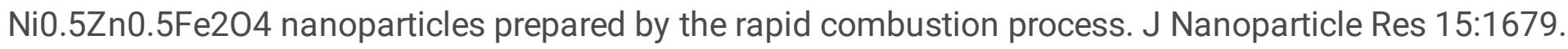
https://doi.org/10.1007/s11051-013-1679-1

Lowell S, Shields JE, Thomas MA, Thommes, M (2004) Characterization of porous solids and powders: surface area, pore size and density. Springer Science, Netherlands.

Lutterotti L, Wenk HR, Matthies S (2010) Maud: Material Analysis Using Diffraction. Versão 2.33. Método RITA/RISTA.

Martins MC, Santos EBH, Marques CR (2017) First study on oyster-shell-based phosphorous removal in saltwater - A proxy to effluent bioremediation of marine aquaculture. Sci Total Environ 574:605-615. https://doi.org/10.1016/j.scitotenv.2016.09.103 
Mohanty K, Jha M, Meikap BC, Biswas MN (2005) Preparation and characterization of activated carbons from Terminalia Arjuna nut with zinc chloride activation for the removal of phenol from wastewater. Ind Eng Chem Res 44:4128-4138. https://doi.org/10.1021/ie050162+

Mousavian NA, Mansouri N, Nezhadkurki F (2017) Estimation of heavy metal exposure in workplace and health risk exposure assessment in steel industries in Iran. Measurement 102:286-290. https://doi.org/10.1016/j.measurement.2017.02.015

Mubarak NM, Alicia RF, Abdullah EC, Sahu JN, Ayu Haslija AB, Tan J (2013) Statistical optimization and kinetic studies on removal of Zn2+ using functionalized carbon nanotubes and magnetic biochar. $J$ Environ Chem Eng 1:486-495. https://doi.org/10.1016/j.jece.2013.06.011

Mullai P, Yogeswari MK, Vishali S, Namboodiri MMT, Gebrewold BD, Rene ER, Pakshirajan k (2017) Aerobic Treatment of Effluents from Textile Industry. In: Lee D-J, Jegatheesan V, Ngo HH, Hallenbeck PC, Pandey A (ed) Current Developments in Biotechnology and Bioengineering, Elsevier, pp 3-34. doi:10.1016/B978-0-444-63665-2.00001-1

Nabais JMV, Nunes P, Carrott PJM, Carrott MMLR, García AM, Díaz-Díez MA (2008) Production of activated carbons from coffee endocarp by $\mathrm{CO}_{2}$ and steam activation. Fuel Process Technol 89:262-268. https://doi.org/10.1016/j.fuproc.2007.11.030

Ogundele LT, Owoade OK, Hopke PK, Olise FS (2017) Heavy metals in industrially emitted particulate matter in Ile-Ife, Nigeria. Environ Res 156: 320-25. https://doi.org/10.1016/j.envres.2017.03.051

PCPDFWIN, (1996) International Center for Diffraction Data, Version 1.20 JCPDS-ICCD.

Reddy KSK, Shoaibi AA, Srinivasakannan C (2013) A comparison of microstructure and adsorption characteristics of activated carbons by $\mathrm{CO}_{2}$ and $\mathrm{H}_{3} \mathrm{PO}_{4}$ activation from date palm pits. Carbon 52:623. https://doi.org/10.1016/j.carbon.2012.10.021

Rodriguez-Reinoso F, Molina-Sabio M, González M (1995) The use of steam and $\mathrm{CO}_{2}$ as activating agents in the preparation of activated carbons. Carbon 33:15-23. https://doi.org/10.1016/0008-6223(94)00100E

Ruthiraan M, Abdullah EC, Mubarak NM, Noraini MN (2017) A promising route of magnetic based materials for removal of cadmium and methylene blue from wastewater. J Environ Chem Eng 5:14471455. https://doi.org/10.1016/j.jece.2017.02.038

Ruthiraan M, Mujawar NM, Kogiladas TR, Abdullah EC (2015) Comparative kinetic study of functionalized carbon nanotubes and magnetic biochar for removal of $\mathrm{Cd}^{2+}$ ions from wastewater. Korean $\mathrm{J}$ Chem Eng 32:446-457. https://doi.org/10.1007/s11814-014-0260-7 
Santos PF, Luz PP (2020) Synthesis of a Ce-Based MOF-76 with High Yield: A Study of Reaction Parameters Based on a Factorial Design. J Braz Chem Soc 31:566-573. https://doi.org/10.21577/01035053.20190218

Silva VA, Rezende MC (2018) Effect of the Morphology and Structure on the Microwave Absorbing Properties of Multiwalled Carbon Nanotube Filled Epoxy Resin Nanocomposites. Mat Res 21:20170977. https://doi.org/10.1590/1980-5373-mr-2017-0977.

Sing KSW (1985) Reporting physisorption data for gas/solid systems with special reference to the determination of surface area and porosity. Pure Appl Chem 57:2201-2218.

https://doi.org/10.1351/pac198254112201

Stat Soft. Inc. (2014). STATISTICA (data analysis software system), version 12. www.statsoft.com.

Sun K, Jiang JC (2010) Preparation and characterization of activated carbon from rubber-seed shell by physical activation with steam. Biomass Bioenerg 34:539-544.

https://doi.org/10.1016/j.biombioe.2009.12.020

Tao T, Li G, He Y, Duan P (2019) Hybrid carbon nanotubes/graphene/ nickel fluffy spheres for fast magnetic separation and efficient removal of organic solvents from water. Mater Lett 254:440-443. https://doi.org/10.1016/j.matlet.2019.06.104

Teixeira MA (2008) Babassu-A new approach for an ancient Brazilian biomass. Biomass and Bioenergy 32:857-864. https://doi.org/10.1016/j.biombioe.2007.12.016

Thines KR, Abdullah EC, Mubarak NM, Ruthiraan M (2017) Synthesis of magnetic biochar from agricultural waste biomass to enhancing route for wastewater and polymer application: A review. Renew Sustain Energy Rev 67:257-276. https://doi.org/10.1016/j.rser.2016.09.057

Tong K, Lin A, Ji G, Wang D, Wang X (2016) The effects of adsorbing organic pollutants from super heavy oil wastewater by lignite activated coke. J Hazard Mater 308:113-119.

https://doi.org/10.1016/j.jhazmat.2016.01.014

Tong K, Zhang Y, Fu D, Meng X, An Q, Chu PK (2014) Removal of organic pollutants from super heavy oil wastewater by lignite activated coke. Colloids Surfaces A Physicochem Eng Asp 447:120-130.

https://doi.org/10.1016/j.colsurfa.2014.01.062

Zanoteli K, Freitas JCC, Silva PRN (2014) Study of nickel catalysts prepared from rice husk ash for the reaction of methane reforming with carbon dioxide. Quim Nova 37:1657-1662. https://doi.org/10.5935/0100-4042.20140272.

Zieliński M, Wojcieszak R, Monteverdi S, Mercy M, Bettahar MM (2007) Hydrogen storage in nickel catalysts supported on activated carbon. Int J Hydrog Energy 32:1024-1032. https://doi.org/10.1016/j.catcom.2005.07.001 
Figures

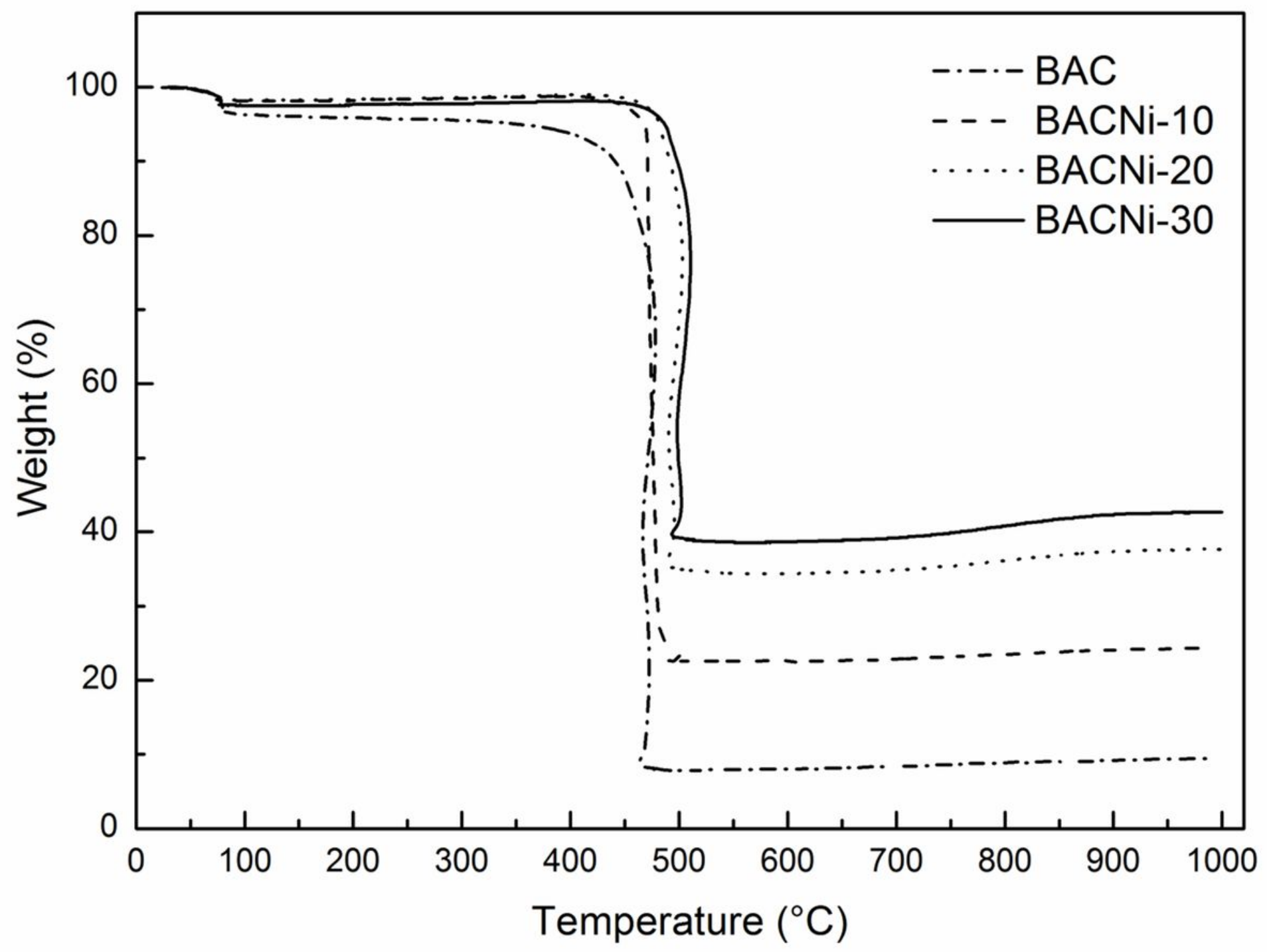

Figure 1

TG curves of the hybrid BACNi-10, BACNi-20 e BACNi-30 samples, under oxidizing atmosphere 


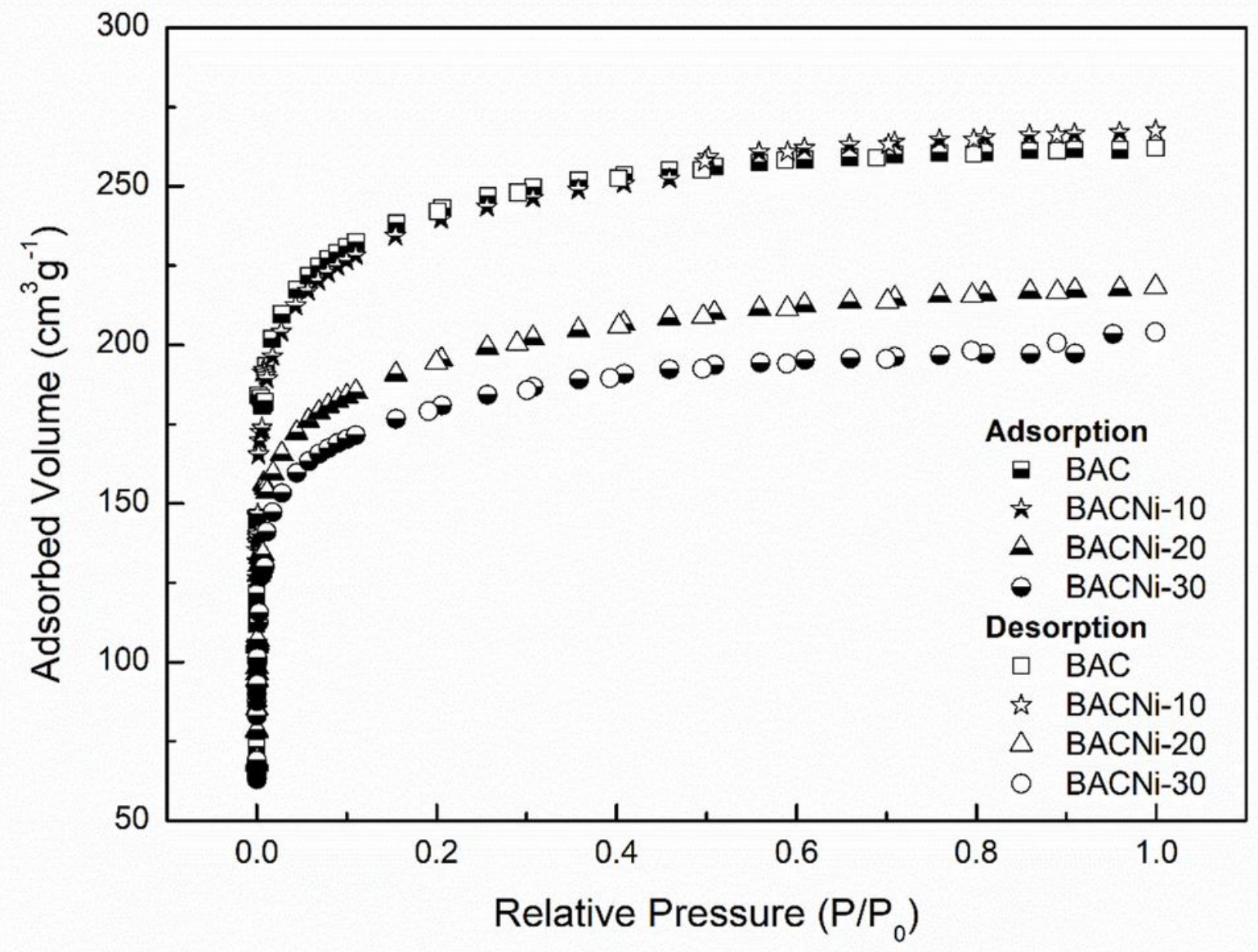

Figure 2

N2 adsorption/desorption isotherms of the pure BAC and hybrid BACNi-10, BACNi-20, BACNi-30 samples 

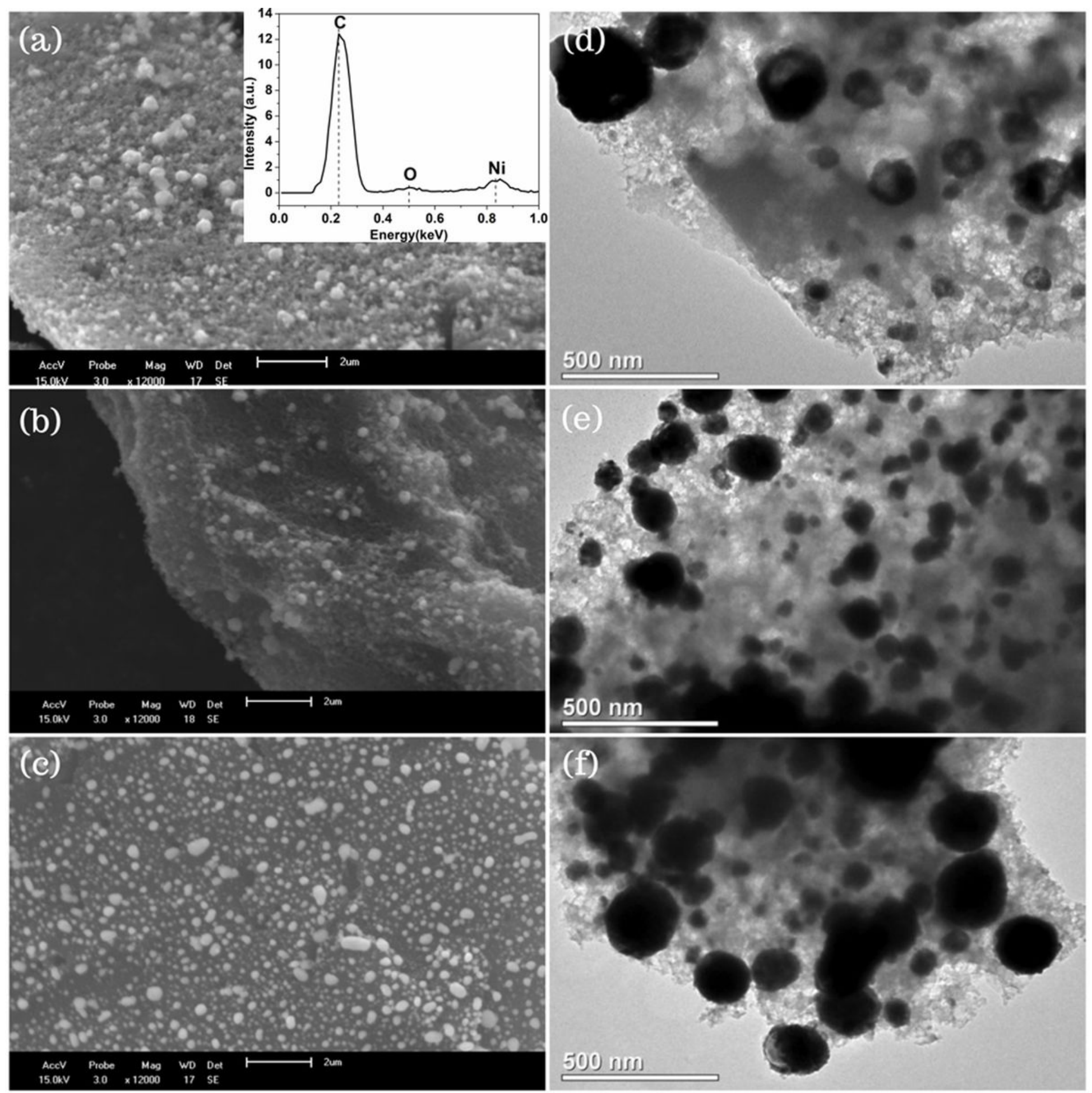

Figure 3

SEM images of the hybrid (a) BACNi-10 (EDX spectrum in the inset), (b) BACNi-20 and (c) BACNi 30 samples, and TEM images of the hybrid (d) BACNi-10, (e) BACNi-20 and (f) BACNi 30 samples 


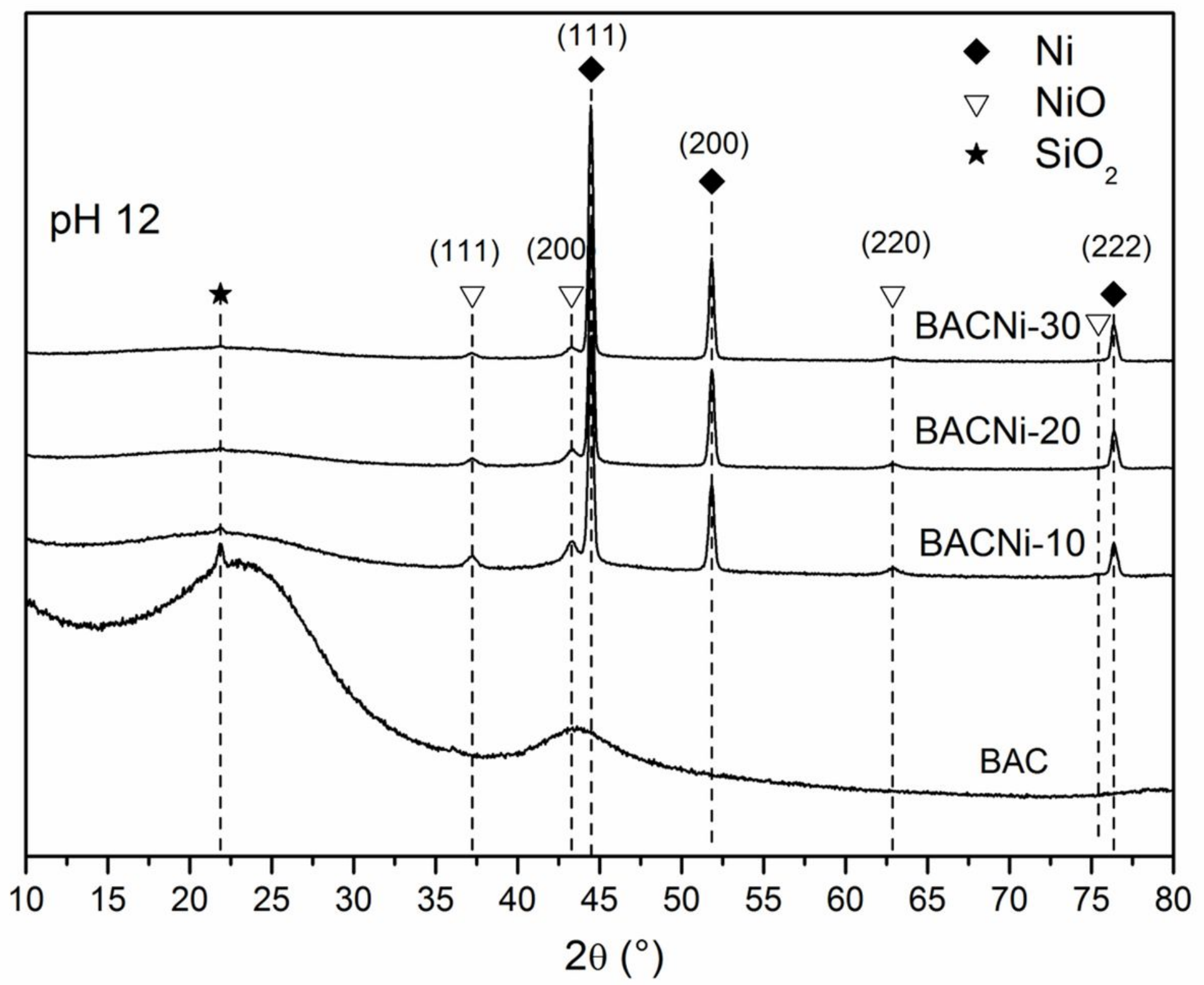

Figure 4

X-ray diffractograms of the pure BAC and hybrid BACNi-10, BACNi-20 and BACNi-30 samples 


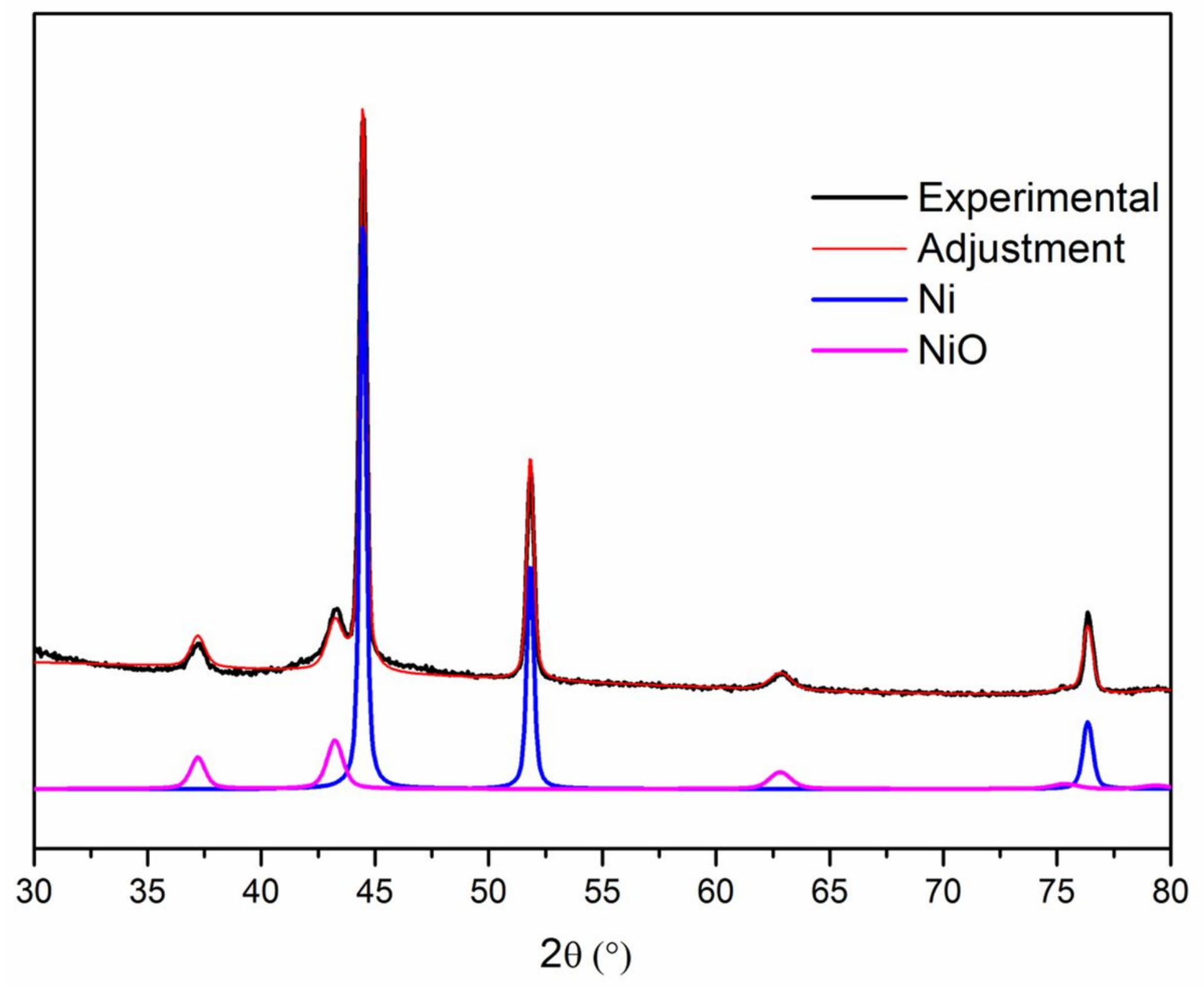

Figure 5

Experimental and simulated PXRD patterns of the hybrid BACNi-10 sample. The simulated pattern was obtained by structure refinement, considering the contributions of the two indicated phases ( $\mathrm{Ni}$ and $\mathrm{NiO}$ ) 


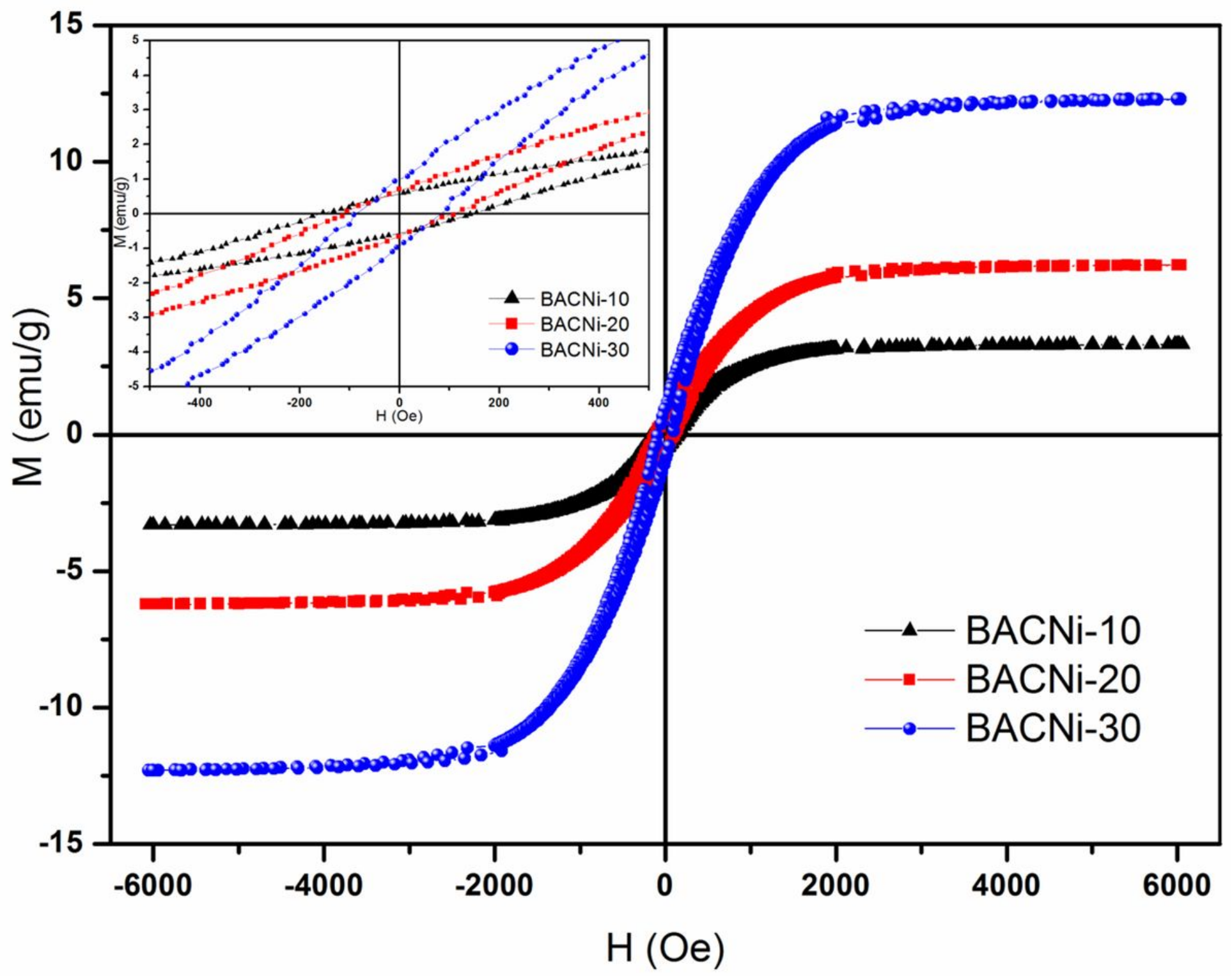

Figure 6

$M(H)$ curves recorded at room temperature for the hybrid BACNi-10, BACNi-20 and BACNi-30 samples 


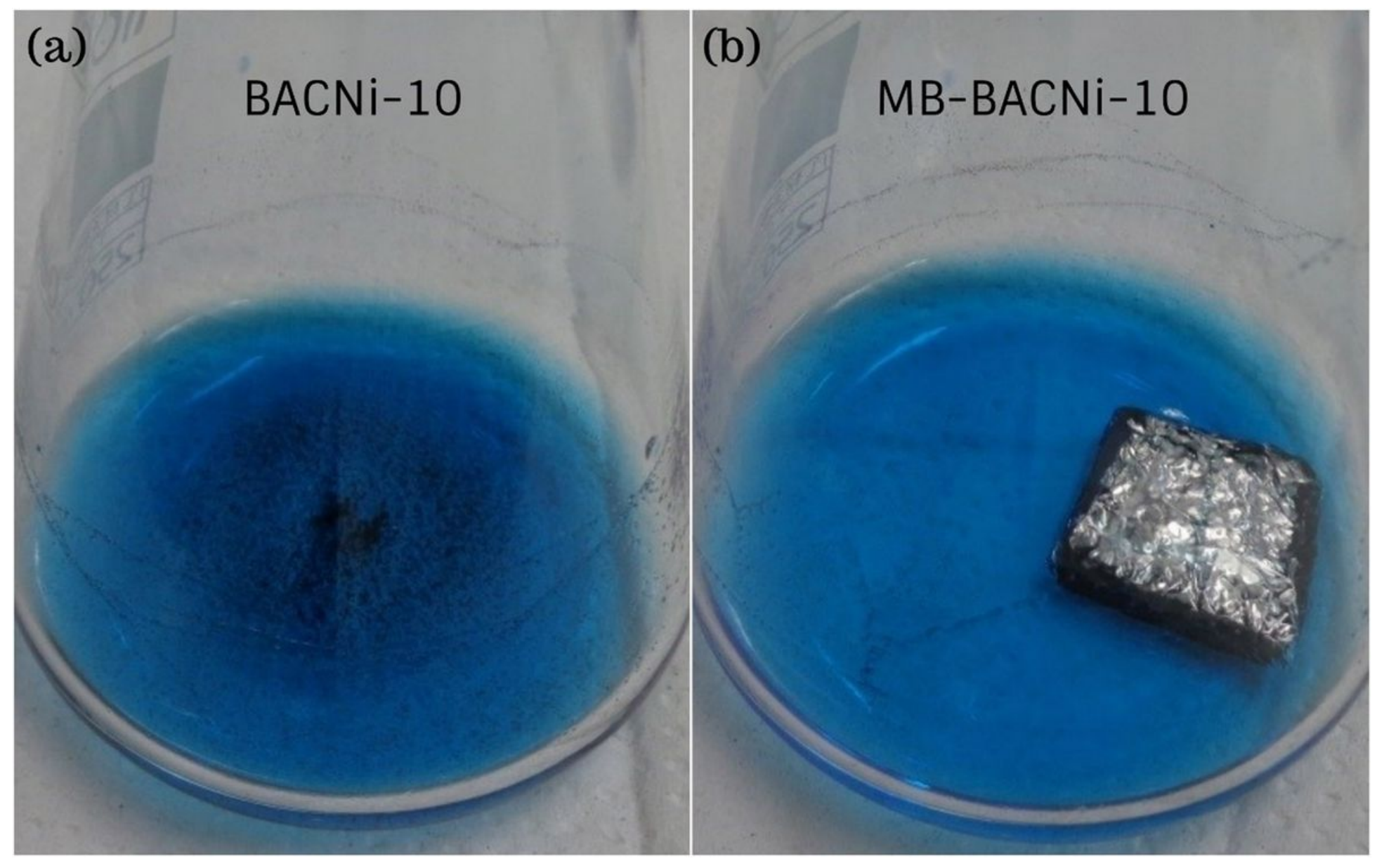

Figure 7

MB adsorption process: (a) dispersion of the hybrid BACNi-10 particles in the concentrated MB solution; (b) removal of the hybrid MB-BACNi-10 particles by the magnet 
Fitted Surface; Variable: MB solution concentration (ppm)

23 -level factors, 1 Blocks, 9 Runs; MS Residual=,8109611 DV: MB solution concentration ( $\mathrm{ppm})$

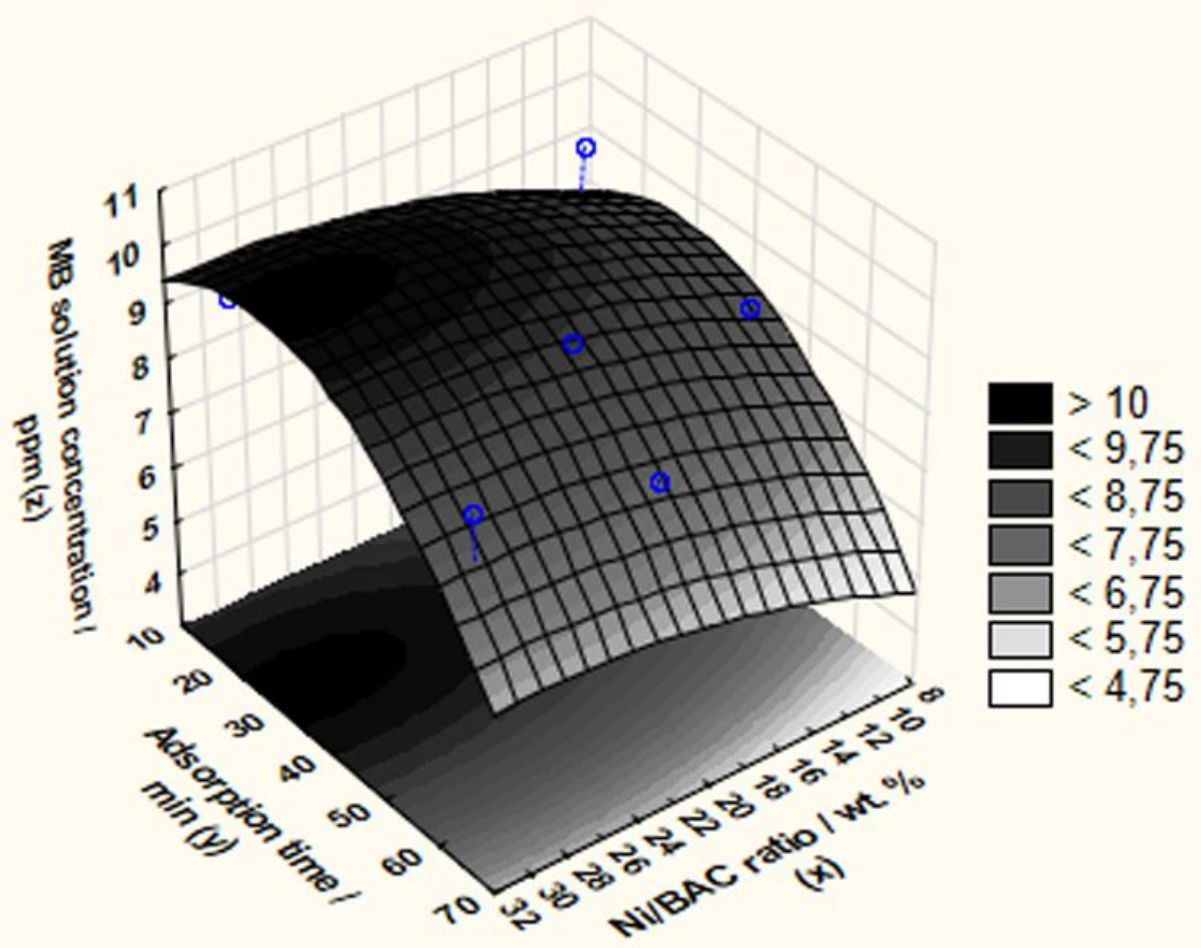

Figure 8

Surface Graph of methylene blue adsorption process by hybrid BACNi-X samples 